\title{
An investigation of the English proficiency of potential nurses from University College Shahputra and Kolej Kejururawatan by Occupational English Writing Test: A case study.
}

\author{
Jebunnesa, Professor Dr. Abdullah bin Ibrahim \\ Faculty of Technology, University Malaysia Pahang \\ Faculty of Technology, University Malaysia Pahang
}

\begin{abstract}
Health practitioners have to demonstrate that their English language proficiency meets certain standards. Being an important part of the healthcare team, nurses who work in multi-lingual context need to have necessary command in English to perform their duties effectively. Though Malaysia is a country full of diverse people, there is no specific English language test for Malaysian nurses now. This research aims to experiment a special test, the Occupational English Writing Test (OET) which is specifically designed for health practitioners, on the nurses of two nursing colleges in Kuantan, Pahang, Malaysia. Specifically the objectives of this research are to assess Malaysian nurses' performance in the OET and to evaluate its suitability and acceptability in Malaysian context. This study is a case study. The nurses chosen as samples for this research cover 53 nursing students from Kolej Kejururawatan, Kuantan and University College Shahputra, Kuantan. The researcher administers a questionnaire which comprises of three sample OET writing tests. She also interviews some samples individually. The result of this study shows that nurses' English proficiency is not satisfactory. The interviews obviously signify that nurses' lack of communication is a barrier to patient safety. Therefore the nurses need to demonstrate a good communication skill in working context. Thus their language proficiency needs to be tested and OET is suitable for this purpose because OET exemplifies the real difficulty of language performance of health practitioners in work-related context. From the research, it is also crystal clear that OET is very much acceptable for Malaysian nurses.
\end{abstract}

Keywords - Nurses today, OET and Malaysia, Case study and results.

\section{Introduction}

"Nurses are the bedrock of highly functioning health systems in all countries," said Evangeline Javier [1]. Nurses today are involved in developing their professional identity as physicians, scientists and educators by proclaiming their position in the health care system [2]. Today's nurses work and live in a multicultural society where they encounter patients whose backgrounds are different from them, and who need care from nurses who are both proficient in their work and knowledgeable about the role that culture plays in patient treatment. Communication through language forms an integral part of conveying meaning and understanding for nurses. Therefore for effective caring, nurses who works in a diverse context need a good communication skill in English, that is, it is needed to check if they have sufficient knowledge of English. Although poor communication can lead to tragic consequences, effective communication can lead to the following positive outcomes: improved information flow, more effective interventions, improved safety, enhanced employee morale, increased patient and family satisfaction, and decreased lengths of stay.

Occupational English Test, an English for Specific Purpose test for health practitioners, is intended to check if the health professionals from Non-English speaking background have sufficient knowledge of English language to communicate and work in a diverse context. OET is accepted by the managing authorities of most major health professions across Australia, New Zealand and Singapore. OET is suitable to be used in multilingual context. Malaysia is a highly multi-cultural and multi-linguistic country and it has significant involvement for Malaysian nurses and other health care professionals who render trans-cultural health services to the migrants living [3]. Thereby to give proper medication to these diverse people, Malaysian heath practitioners, especially nurse practitioners must need sufficient knowledge in English and a test like OET is also needed for them.

\section{Material and methods}

This study employs a case study involving 53 nurses of two nursing colleges in Kuantan. The case study, as the term suggests, is the study of "particularity and complexity of a single case" [4]. In a case study, cases are mainly people but a program, an institution, an organization or a community can also be considered as case. Here the cases are the nursing students of Kuantan Nursing College and of University College Shahputra. 
A questionnaire, a set of tests which are revised from three OET sample writing test, is used as research instrument for this research. This study also uses interview as data gathering instrument. It utilizes semi-structured interviews in a face to face interaction to explore the subjects' beliefs and thoughts about certain topics; as Lynch (1996) opined that, the use of semi-structured interviews increases the comprehension of the data and makes the data collection more orderly or systematical than the informal conversational approach. The raw data is analyzed and organized manually based on three variables.

\section{Results and Discussion}

A writing test was administered on 31 nursing students of Kolej Kejururawatan, Kuantan on $5^{\text {th }}$ October and on 22th November on 22 nursing students of University College Shahputra. After the writing test, ten nurses were also interviewed individually from each college. The test question included three tests which were revised from three sample writing test of OET based on the pilot test. The Respondents had to write three referral letters based on some biological case notes of patients. As the samples are many in number, the researcher analyzes the samples' performances based on three variables for convenience of organization. The assessment criteria and variables are described in table 3.1.

From the results, it is found that students answer very spontaneously. Though they have to answer three tests at a time, only 7 samples escape some parts of the test among 53 samples. Their performance is not satisfactory. Among 53 students, 24 students get poor, 2 students get good and the remaining 27 get satisfactory score on average. It is also noticeable that most of the students' grammar is not good but their score in grammar is not satisfactory. In the interview also, all the students except one said that the test is difficult to them and note forms are difficult for them to extend which also indicates their poor grammar.

5 nurses from Kuantan Nursing College and 5 nurses from University College Shahputra are also interviewed individually. During the interview, most of them opine that the test is difficult. Among 10 interviewees, 6 respondents consider the test as difficult, 3 as easy and 1 as middle. All the interviewees unfold that nurses lack of communication skill can create many problems in medication. So their grammar, vocabulary, speaking and other language ability should be tested. Besides, all the respondents opine that OET is suitable for Malaysia.

\section{Figures and Tables}

Table 3.1

Assessment criteria for the writing test

\begin{tabular}{|l|l|l|l|}
\hline Assessment criteria & Content (variable) & Grammar (variable) & Format (variable) \\
\hline Excellent & $\begin{array}{l}\text { Intensely well } \\
\text { organized and developed }\end{array}$ & $\begin{array}{l}\text { Excellent command of } \\
\text { grammar }\end{array}$ & Very effectively formatted \\
Well organized and & $\begin{array}{l}\text { Good command of } \\
\text { grammar }\end{array}$ & Effectively formatted \\
\hline Average & $\begin{array}{l}\text { Satisfactorily organized and } \\
\text { developed }\end{array}$ & $\begin{array}{l}\text { Basic knowledge of } \\
\text { grammar }\end{array}$ & Basic knowledge of the format \\
Disorganized and not & $\begin{array}{l}\text { Great difficulty in writing } \\
\text { accurate sentence }\end{array}$ & $\begin{array}{l}\text { Limited elements of format are } \\
\text { found }\end{array}$ \\
\hline
\end{tabular}

\section{Conclusion}

This study is an endeavor to understand Malaysian nurses' performance in Occupational English Writing Test and to assess its suitability in Malaysian context.The result of this study which is conducted by OET sample writing test and especially the interviews obviously signify that nurses' lack of communication is a barrier to standard care. Therefore their language proficiency needs to be tested and OET is suitable for this purpose because OET exemplifies the real difficulty of language performance of health practitioners in workrelated environment. OET is more appropriate to the nurses than general language tests because it reflects the actual communicative needs of medical professionals. OET is very much acceptable to the nurses as all the samples said in the interview that OET is suitable for Malaysian nurses.

\section{REFERENCES}

[1] Camara, P. D., and Jackson, S. Nursing shortage in the English-speaking Caribbean hinders the region's development, Says World Bank report, The World Bank: News and Broadcast, 2010; 278, retrieved from: http://web.worldbank.org.

[2] Allen, S.The importance of language for nursing: does it convey Commonality of meaning and is it important to do so,Australian Journal of Advanced Nursing, 24 (4), 2007; 47-51.

[3] Chang, K. H. Trans-cultural Mental Health Nursing in Malaysia: Perspectives and Strategies, Contemporary Nurse: A Journal for Australian Nursing Profession., 34(2), 2010; 134-135.

[4] Stake, R. The Art of case study research (Thousand Oaks, CA: Sage, 1995). 